\title{
Abstract \\ Exploiting DNA Repair Defect in Triple Negative Breast Cancer Using CDK Inhibition Strategy ${ }^{\dagger}$
}

\author{
Carolina Velázquez ${ }^{1,2, *}$, Esin Orhan ${ }^{1, *}$, Imene Tabet ${ }^{1}$, Lise Fenou ${ }^{1,2}$, Laura Boudarel ${ }^{1}$, William Jacot ${ }^{1,2}$, \\ Claude Sardet ${ }^{1}$ and Charles Theillet ${ }^{1,2}$
}

1 IRCM, Institut de Recherche en Cancérologie de Montpellier U1194 INSERM, Université de Montpellier, 34090 Montpellier, France; Imene.tabet@inserm.fr (I.T.); Lise.fenou@icm.unicancer.fr (L.F.);

Laura.boudarel@inserm.fr (L.B.); William.Jacot@icm.unicancer.fr (W.J.); Claude.sardet@inserm.fr (C.S.); Charles.theillet@inserm.fr (C.T.)

2 ICM, Institut du Cancer de Montpellier, 34090 Montpellier, France

* Correspondence: carolina-velazquez@hotmail.com (C.V.); Esin.orhan@inserm.fr (E.O.)

+ Presented at the 1st International Electronic Conference on Cancers: Exploiting Cancer Vulnerability by Targeting the DNA Damage Response, 1-14 February 2021; Available online: https:/ /iecc2021.sciforum.net/.

Citation: Velázquez, C.; Orhan, E.; Tabet, I.; Fenou, L.; Boudarel, L.; Jacot, W.; Sardet, C.; Theillet, C. Exploiting DNA Repair Defect in Triple Negative Breast Cancer Using CDK Inhibition Strategy. Med. Sci. Forum 2021, 3, 13. https: / doi.org/10.3390/IECC202109212

Academic Editors: Nicola Curtin and Helen E. Bryant

Published: 29 January 2021

Publisher's Note: MDPI stays neutral with regard to jurisdictional claims in published maps and institutional affiliations.

Copyright: (c) 2021 by the authors. Licensee MDPI, Basel, Switzerland. This article is an open access article distributed under the terms and conditions of the Creative Commons Attribution (CC BY) license (https:// creativecommons.org/licenses/by/ $4.0 /)$.
Abstract: Triple-negative breast cancer (TNBC), representing 15\% of breast carcinomas, is an aggressive breast cancer subtype with a high probability of metastasis and limited treatment options. Noticeably, BRCA-deficiency occurs in $25 \%$ of the TNBCs and results in deficient homologous recombination (HR) repair. Interestingly, PARP inhibitors (PARPi) have shown synthetic lethality in a BRCA-deficient context; however, their efficacy is frequently hampered by intrinsic or acquired resistance mechanisms involving restoration of the HR. In that regard, the role of some CDKs proven to regulate key HR actors was of interest to us. In this study, we aimed to understand the rewiring pathways determining resistance to PARPi in BRCA-deficient cancers and to assess the role of transcriptional regulating CDKs such as CDK7, CDK9, or CDK12 in the transcriptional regulation of key HR genes. Our ultimate goal was to determine whether and which CDK inhibitors could be effective approaches to repress HR gene expression and induce pharmacological HR-deficiency. As such, these CDK-inhibitors (CDKi) could be molecules of choice allowing sensitization of tumors that would otherwise respond poorly to DNA damaging treatment. With this purpose, we used in vitro and in vivo (PDX) models of TNBC and studied the attenuation of the HR response in tumor cells and PDX models treated with CDK-inhibitors. Our final aim was to determine the most efficient combination of CDKi and PARPi Our HR read outs were RAD51 and BRCA1 foci formation upon PARPi treatment. We also measured the modification of RNA and protein expression levels induced by CDKi treatment on a series of diagnostic HR genes (BRCA2, PALB2, ATR, FANCD2), as a measure of $\mathrm{HR}$ repression. We present data comparing the relative efficiency of three $3 \mathrm{CDKi}$; dinaciclib, NVP-2, and SR-4835, which have different specificities and inhibit different CDKs with variable efficacy.

Keywords: Triple Negative Breast Cancer; PARP; CDK; DNA damage; homologous recombination; BRCA-deficiency

Supplementary Materials: Velazquez et al. Poster is available online at: https:/ /www.mdpi.com/ article/10.3390/IECC2021-09212/s1.

Institutional Review Board Statement: The study was reviewed and approved by the ethics committees of the IRCM INSERM U1194 and the University of Montpellier animal (CEEA-LR-12028) approval \# 2018112314153027.

Informed Consent Statement: Informed consent was obtained from all subjects involved in the study.

Data Availability Statement: Data sharing not applicable. 